\title{
Effects of ultra-high hydrostatic pressure on foaming and physical-chemistry properties of egg white
}

\author{
Rui-Xiang Yang, Wen-Zhao Li, Chun-Qiu Zhu, Qiang Zhang
}

Key Laboratory of Food Nutrition and Safety, Tianjin University of Science \& Technology, Tianjin, China. Email: yrxsky@126.com

Received 11 July 2009; revised 1 September 2009; accepted 2 September 2009.

\begin{abstract}
The influences of ultra-high hydrostatic pressure treatment on foaming and physical properties (solubility, hydrophobicity and sulfhydryl content) of egg white were investigated. A pressure range of 0-500 MPa, time range of 0-20 $\mathrm{min}$ and $\mathrm{pH}$ range of 7.5-8.5 were selected. The foaming property of egg white is improved by $350 \mathrm{Mpa}$ and $10 \mathrm{~min}$. The treatment resulted in increase of sulfhydryl content of egg white, while solubility and hydrophobicity were significantly decreased.
\end{abstract}

Keywords: Ultra-High Hydrostatic Pressure; Egg White; Foaming Property

\section{INTRODUCTION}

Egg white is well known for their high nutritional quality, foaming, gelling and emulsifying characteristics, which can give the foods unique color, flavor, and texture characteristics. Therefore, as an important ingredient, egg white has been wildly applied in the food industry, such as cakes, biscuits, breads, ice cream, and other protein products [1]. At present, for convenience and safety, liquid egg white products are widely used by home and producer. However, decrease of the foaming property after pasteurization is found in practice, which seriously affects the application and development of the egg white products.

Ultra-high static pressure technology is a new sterilization technology, which can be used to resolve the problems brought by pasteurization. Ultra-high pressure can improve the function of biological macromolecules by modifying their structure [2]. The high pressure does not affect the primary structure of protein molecules, but can cause agglutination of protein by changing the hydrogen bonds, disulfide bonds and hydrophobic groups among the protein molecules. In addition, ultra-high hydrostatic pressure can cause viscosity and surface tension of egg white increased [3]. The relationship between foaming property and solubility, hydrophobicity, sulfhydryl content under ultra-high hydrostatic pressure is also investigated in this paper, and only the irreversible changes in the properties are taken into account.

\section{MATERIALS AND METHODS}

\subsection{Materials and Equipments}

Fresh eggs were obtained from supermarket. Eggshell was washed by clean water and exposed to ultraviolet light for $30 \mathrm{~min}$ to disinfect. The egg white was separated from egg yolk and the chalazae were removed. The albumin was gently mixed and stored at $4{ }^{\circ} \mathrm{C}$ until use. The protein content of the egg white was determined to be $11.23 \pm 0.56 \%(\mathrm{w} / \mathrm{v})$.

\subsection{Ultra-High Hydrostatic Pressure Treatment}

A volume of $200 \mathrm{~mL}$ of egg white was packed in polyethylene plastic packs $(170 \times 120 \mathrm{~mm})$ and sealed. The ultrahigh hydrostatic pressure treatment was performed in high pressure equipment (Hpp-M1, Senmiao, China) and a pressure range of 0-600 $\mathrm{MPa}$, time range of 0-20 min were selected in the experiment. All samples were analyzed at room temperature after 24 -hour storage at $4^{\circ} \mathrm{C}$.

\subsection{Determination of Foaming Property}

A volume of $35 \mathrm{~mL}\left(18 \sim 25^{\circ} \mathrm{C}\right)$ egg white was placed in a graduated cylinder of $250 \mathrm{~mL}$ (diameter $=398 \mathrm{~mm}$ ) and whipped for $5 \mathrm{~min}$ (which is an optimal time for whipping egg white in this measurement system in previous study) with a rotating anchor $(275 \mathrm{~mm}$ diameter, rotor from the bottom of the graduated cylinder $15 \mathrm{~mm}$ ) at $2100 \mathrm{rpm}$, using a laboratory stirrer with controlled constant speed (OJ-100, Onuo, China). The volume of foam $\left(\mathrm{V}_{0}\right)$ was recorded immediately after the whipping stopped. The foaming capacity (FC) [4] was defined by

$$
F C(\%)=\frac{V_{0}}{35} \times 100 \%
$$

The volume of drainage of liquid $\left(\mathrm{V}_{\mathrm{d}}\right)$ was recorded at $10 \mathrm{~min}$, The foam stability was defined by 


$$
\text { Drainage }(\%)=\frac{V_{d}}{V_{0}} \times 100 \%
$$

Samples were determined in triplicate.

\subsection{Determination of Solubility}

Samples were centrifuged during $10 \mathrm{~min}$ at 10,000 r/min and $18^{\circ} \mathrm{C}$. Protein content of the supernatant was determined.

\subsection{Determination of Sulfhydryl Content}

The concentration on sulfhydryl ( $\mathrm{SH}$ ) groups of the egg white solutions was determined using Ellman's reagent (5', 5-dithiobis (2-nitrobenzoic acid), DTN-B). $1 \mathrm{~mL}$ of sample add to $4 \mathrm{~mL}$ of $0.05 \mathrm{~mL} 0.01 \mathrm{M}$ DTNB in phosphate buffer $(0.1 \mathrm{M}, \mathrm{pH} 8.0)$, after $20 \mathrm{~min}$ of mixing, the reaction mixture was centrifuged during $15 \mathrm{~min}$ at $10,000 \mathrm{r} / \mathrm{min}$ to remove precipitated protein. Finally, the absorbance of the supernatant was measured at $412 \mathrm{~nm}$ against a reagent blank. A blank sample in which DTNB was substituted by phosphate-buffer was carried through in parallel. The sulfhydryl content is expressed as a mole thiol/globulin grams $=\mathrm{n} \mathrm{mol} / \mathrm{mg}$ protein [5].

\subsection{Determination of Surface Hydrop-Hobicity}

The determination of the protein hydrophobic domains through Takagi [4] approach, using 8-aniline-based-1Chennai acid (referred to as ANS). Each sample was diluted with the $0.1 \mathrm{M}$ phosphate buffer (pH6.8), until the protein concentration of $0.05 \%, 4.5 \mathrm{~mL}$ of the diluted sample and $0.5 \mathrm{~mL} 1.25 \times 10^{-3} \mathrm{~m}$ ANS mixed phosphate buffer. Placing at room temperature for two hours, the fluoresceence intensity was measured (excitation wavelength $375 \mathrm{~nm}$, Kaloula $1.0 \mathrm{~nm}$, emission wavelength of 420-600nm (475nm), Kaloula 1.0nm, medium-speed scanning speed). Globulin in the hydrophobic region is expressed as fluorescence intensity and protein concentration of $0.05 \%$.

\section{RESULTS AND DISCUSSIONS}

\subsection{Effect of High Hydrostatic Pressure on Foaming C Property of Egg White}

Foaming property is one of the most important surface characteristic of protein molecule. Albumin proteins are typical amphiphilic molecules, which are easy to extend on the water-air interface and adsorb gas in the whipping process. It has been verified that globulin and albumin of egg white play a major role in forming bubble; Ovomucin and egg lysozyme are favorable for foaming stability [1]. Iesel Plancken has shown that the foaming property of egg white is mainly relative to the content of sulfhydryl and the flexibility of protein molecule. The interaction between protein and protein can improve the foaming stability of egg white [2].

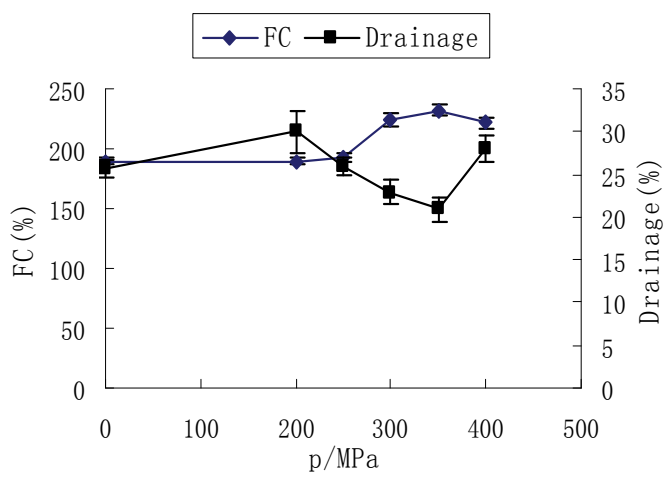

Figure 1. Effect of pressure on foaming property of egg white $\mathrm{pH}=8.1, \mathrm{t}=10 \mathrm{~min}, 18^{\circ} \mathrm{C}$.

There are not significant changes for FC between $0-200 \mathrm{MPa}$, as can be seen in Figure 1. But the drainage is increasing and reaches the maximum at $200 \mathrm{MPa}$, which means the worst foam stability. With the pressure increasing, the $\mathrm{FC}$ is still rising until $350 \mathrm{MPa}$, but the drainage has been decreasing and reaches the minimum at 350 $\mathrm{MPa}$. According to the relevant literature, the phenomenon above was analyzed as follows. It is known that practical aggregation of proteins can raise the protein foaming capability and stability [4]. In this process, aggregation affection can enhance the reaction among proteins and make them become precipitate or gel. While the protein gel appears, the foaming capability and stability will decline sharply.

\subsection{Effect of Time on Foaming Property of Egg White}

As can see from Figure 2, with the extension of processing time, the foaming capability increases and reaches the maximum at $10 \mathrm{~min}$. While the drainage drops to the lowest, there is the best foaming stability. It indicates that in the aggregation of protein process, $10 \mathrm{~min}$ is suitable for foaming characteristic of egg white. According to the relevant report, the $\beta$-sheet structures of

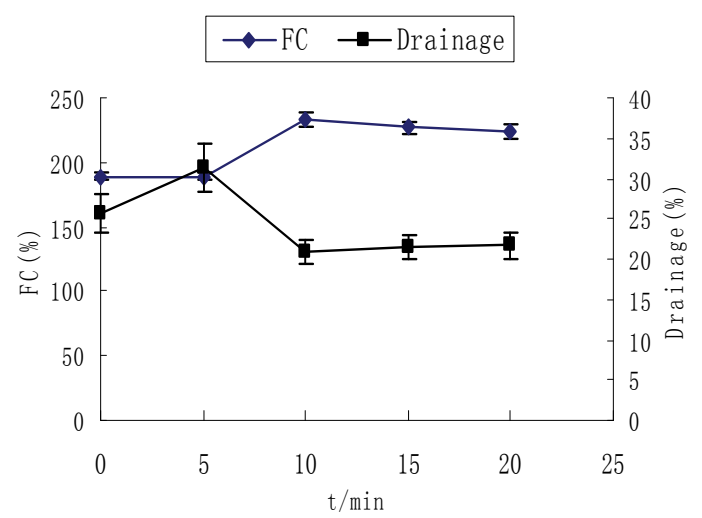

Figure 2. Effect of time on foaming property of egg white $\mathrm{p}=350 \mathrm{MPa}, \mathrm{pH}=8.2,18^{\circ} \mathrm{C}$. 
protein treated with the pressure are unfolded, which can improve the ability of maintaining gas for egg white and make it easy to form bubble [4]. And also, it has enhanced the interaction among proteins, which is favorable for foaming stability. After 10min, the protein precipitate starts to appear, and the foaming capability is decreasing. The previous studies have shown that when egg white is treated by $350 \mathrm{Mpa}$ for $10 \mathrm{~min}$, the surface tension and viscosity is increasing [3]. From the phenomenon and the relevant conclusion above, we can draw a conclusion as follows: ultra-high pressure treatment can change the structure of protein molecules and cause aggregation of proteins, which can improve the foaming property of egg white.

Next, 10min was selected for different ultra-high pressure treatment to investigate the relationships between foaming property and other characteristic of egg white.

\subsection{Effect of High Hydrostatic Pressure on Solubility of Egg White}

Protein solubility is an important property of hydration. The protein and water molecules are connected through the interaction of the peptide bond or amino acid side chain (ionization, polar or non-polar group) [1]. As can be seen from Figure 3, the solubility of protein decreases with the pressure increasing. The tertiary and quaternary structures of protein treated by the ultra-high pressure were destroyed for that molecules of protein have been unfolded [4]. The reactions of aggregation among protein molecules have been enhanced, therefore, the solubility of egg white becomes decreasing. Comparing to Figures 1,3, there are not significant linear correlation between the foaming properties and solubility of egg white treated by ultra-high pressure. When the percent of soluble protein is $71 \%$, the foaming property of egg white is better.

\subsection{Effect of High Hydrostatic Pressure on Surface Sulfhydryl Content of Egg White}

As can been seen from Figure 4, there are significant changes of surface sulfhydryl content with pressure

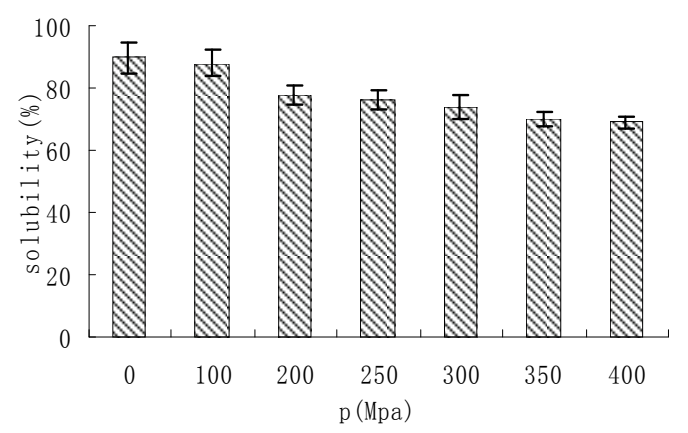

Figure 3. Effect of pressure on solubility of egg white $\mathrm{pH}=8.1, \mathrm{t}=10 \mathrm{~min}, 18^{\circ} \mathrm{C}$. reaching the maximum at $350 \mathrm{MPa}$. When the egg white is treated by ultra-high hydrostatic pressure, the structure of the ovalbumin has been changed, which causes four internal sulfhydryl of c molecule being exposed and in creases the surface sulfhydryl content on the bases of relevant literature. Comparing with Figures 1,5, there is the same trend between the foaming properties and the surface sulfhydryl content of egg white. The foaming capability, stability and surface sulfhydryl content all reach the maximum at $350 \mathrm{Mpa}$.

\subsection{Effect of High Hydrostatic Pressure on Hydrophobicity of Egg White}

As can been seen from Figure 5, the hydrophobic of egg white has the maximum at $100 \mathrm{MPa}$. With the pressure increasing, hydrophobicity of egg white decreases. It is known that hydrophobic interaction is the main force to maintain protein tertiary structure. So we can deduce that the tertiary and quarternary structures of proteins of egg white treated by the ultra-high hydrostatic pressure are destroyed, and more hydrophobic regions are exposed. With the pressure increasing, hydrophobic amino acids are buried and the hydrophobic region is reduced. Therefore, hydro-phobic property of protein decreased.

\section{CONCLUSIONS}

The foaming capability and stability of egg white are im-

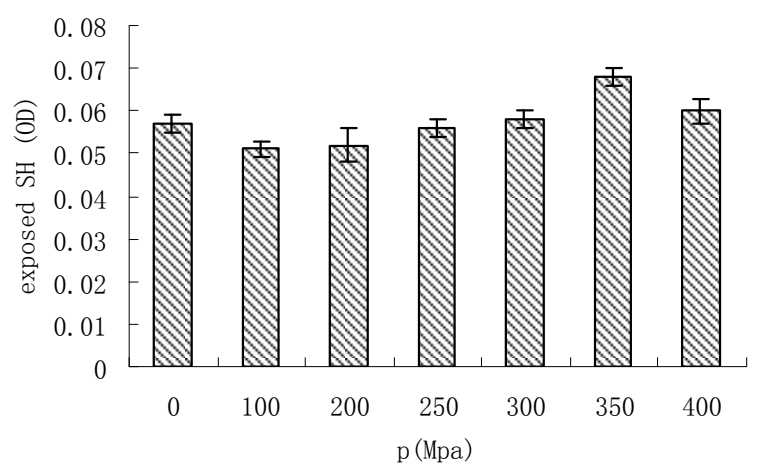

Figure 4. Effect of high hydrostatic pressure on sulfhydryl content of egg white $\mathrm{pH}=8.1, \mathrm{t}=10 \mathrm{~min}, 18^{\circ} \mathrm{C}$.

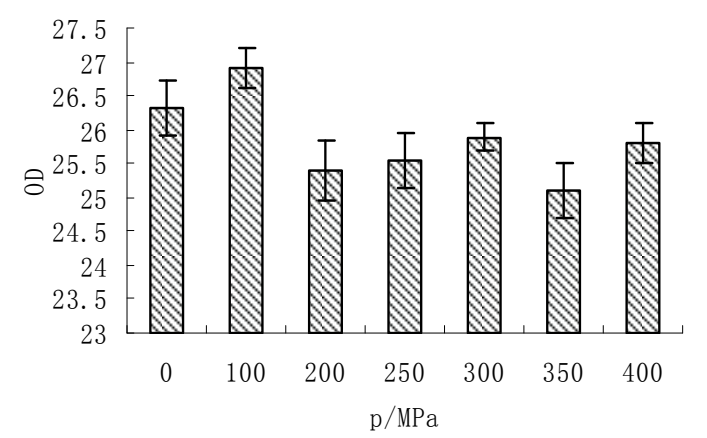

Figure 5. Effect of high hydrostatic pressure on hydrophobicity of egg white $\mathrm{pH}=8.1, \mathrm{t}=10 \mathrm{~min}, 18^{\circ} \mathrm{C}$. 
proved by the ultra-high hydrostatic pressure (100-400 $\mathrm{MPa}$ ), and play the best performance by $350 \mathrm{Mpa}$ and $10 \mathrm{~min}$. The findings of the experiment of physical properties of egg white with ultra-high hydrostatic pressure show that with increasing pressure, the solubility of egg white will decrease. There is positive relation between the surface sulfhydryl content and the foaming properties of egg white. When the hydrophobicity of egg white is the lowest, the foaming capacity and foam stability of egg white will reach the best performance.

\section{ACKNOWLEDGEMENTS}

This research is support by the research fund of personnel of Tianjin University of Science \& Technology.

\section{REFERENCES}

[1] X. D. Li and L. W. Zhang. (2005) Egg Science and
Technology. Chemical Industry Press.

[2] E. V. Plancken, A. VanLoey, and M. E. Hendricks. (2007) Foaming properties of egg white affected by heat or high pressure treatment, Journal of Food Engineering, 78, 1410-1426.

[3] W. Wang and W. Z. Li. (2009) Effect of ultra-high hydrostatic pressure on foaming and physical properties of the egg white. Journal of Tianjin University of Science and Technology, 24, 35-38.

[4] H. Wang and Z. C. Tu. (2008) Egg white protein dynamic modification of ultrahigh-pressure micro jet and mechanism of, Nanchang University.

[5] K. Lomakina. (2005) A study of the factors affecting the foaming properties of egg white-a review. Food Science, 24, 110-118.

[6] J. Liu and B. Jiang. (2007) Effects of ultra-high pressure on foaming property of chickpea protein isolated. Anhui Agricultural Science, 35, 9012-9013. 